\title{
Esophagectomy and substitution of the thoracic esophagus in $\operatorname{dogs}^{1}$
}

\author{
Esofagectomia e substituição do esôfago torácico em cães
}

\author{
Carlos Eduardo Meirelles dos Santos ${ }^{\mathrm{I}}$, Sheila Canevese RahalI", Débora Cristina Damasceno ${ }^{\mathrm{III}}$, Rogério Saad Hossne ${ }^{\mathrm{IV}}$ \\ ${ }^{I}$ Master, Department of Veterinary Surgery and Anesthesiology, School of Veterinary Medicine of Botucatu, UNESP, Sao Paulo, Brazil. \\ ${ }^{\text {II }} \mathrm{PhD}$, Chairman Full Professor, Department of Veterinary Surgery and Anesthesiology, School of Veterinary Medicine of Botucatu, UNESP, Sao Paulo, \\ Brazil. \\ III PhD, Department of Gynecology and Obstetrics, School of Medicine of Botucatu, UNESP, Sao Paulo, Brazil. \\ Iv $\mathrm{PhD}$, Assistant Professor, Department of Surgery, School of Medicine of Botucatu, UNESP, Sao Paulo, Brazil.
}

\begin{abstract}
Purpose: To evaluate a technique to remove the thoracic esophagus without thoracotomy and two methods for thoracic esophageal replacement in dogs. Methods: 27 ex-vivo dogs were divided into three groups in order to evaluate: G1 - total thoracic esophagectomy by the everting stripping method; G2 - total thoracic esophagectomy and esophageal substitution using the whole stomach; G3 - total thoracic esophagectomy and esophageal substitution using fundus rotation gastroplasty. After esophageal resection in G1, the integrity of the intrathoracic route was evaluated by endoscopy and tested with $1 \%$ methylene blue solution. Results: Visceral pleural rupture was observed in all animals. However, this intrathoracic route made it possible to bring both esophagus substitutes (G2 and G3) to be anastomosed to the cut end of the cervical esophagus. Conclusions: Thoracic esophageal substitution using the whole stomach showed less anastomotic tension and was less technically demanding than the fundus rotation gastroplasty method. The ex-vivo results support further studies to validate the techniques in clinical cases.
\end{abstract}

Key words: Surgery. Esophagectomy. Esophagus. Endoscopy. Dogs.

\section{RESUMO}

Objetivo: Avaliar, em cadáveres de cães, uma técnica para remoção do esôfago torácico sem toracotomia e dois métodos de substituição do esôfago torácico. Métodos: Foram utilizados 27 cadáveres de cães. Estes foram aleatoriamente divididos em três grupos de nove animais, em que se estudou: G1 - esofagectomia torácica total pelo método de invaginação retrógrada; G2 - esofagectomia torácica total com substituição esofágica pelo estômago inteiro; G3 - esofagectomia torácica total com substituição esofágica por um gastrotubo confeccionado de acordo com a técnica de Büchler de gastroplastia por rotação do fundo. Após a ressecção esofágica no grupo 1, a integridade da rota intratorácica foi avaliada por endoscopia e solução de azul de metileno a 1\%. Resultados: A ruptura da pleura visceral ocorreu em todos os animais, especialmente no terço caudal. Entretanto, a rota transtorácica mediastinal permitiu a elevação de ambos os substitutos esofágicos (G2 e G3) para a realização da anastomose com a extremidade caudal do esôfago cervical. Conclusões: A substituição por estômago inteiro apresentou menor tensão na anastomose, maior facilidade e rapidez comparada à técnica de gastroplastia por rotação do fundo. Os resultados em cadáveres suportam a realização de estudos clínicos para validação da técnica.

Descritores: Cirurgia. Esofagectomia. Esôfago. Endoscopia. Cães.

${ }^{1}$ Research performed at Experimental Laboratory of Department of Veterinary Surgery and Anesthesiology, School of Veterinary Medicine of Botucatu, State University (UNESP), Sao Paulo, Brazil.

\section{Introduction}

Esophageal diseases have sometimes been considered a therapeutic challenge in dogs. If major areas of the esophagus have been compromised complex surgical procedures to repair, to remove or to substitute the compromised area are required ${ }^{1,2,3}$.

Esophagectomy that consists of a complete or partial resection of the esophagus is usually used in human medicine ${ }^{4}$. Total thoracic esophagectomy is performed, in general, using the transthoracic route, transhiatal approach without thoracotomy or by thoracoscopy. The removed esophagus is replaced using the stomach, colon, or small bowel, and each procedure has advantages and disadvantages ${ }^{5}$. These organs are mobilized to be anastomosed to the cut end of the cervical esophagus using several routes.

The ideal esophageal substitute should conform in size and in function to the original structure especially regarding peristaltic activity; it should not occupy too much space in the thorax; and the patient should be able to swallow normally and experience no reflux symptoms ${ }^{4}$. Additionally, in pediatric patients the esophageal substitute should be able to withstand without deterioration during temporal evolution ${ }^{4}$.

In dogs, thoracic esophageal replacement by small intestine or colon is hampered by limited mobility of the vascular 
pedicle $^{2}$. In addition the use of free colon autograft with microvascular anastomosis has shown unsatisfactory results in experimental studies ${ }^{6}$. In this way, substitutes for the esophagus created from the stomach may be a better alternative.

The use of the whole stomach or gastric tubes as substitutes for the esophagus are common procedures in human patients $^{7}$, but there are few clinical reports of their use in small animals ${ }^{1}$. The present study evaluated a technique to remove the thoracic esophagus without thoracotomy and two methods for thoracic esophageal replacement in dogs, ex vivo, aiming at the treatment of diseases associated with this species.

\section{Methods}

This study followed the guidelines for the care and use of laboratory animals and was approved by the Ethics Committee of our Veterinary School.

Twenty-seven dogs that had died or been euthanatized due to reasons unrelated to this study were used; 12 males and 15 females, weighing 2-20 kg (median $6 \mathrm{~kg}$ ), and aged 2 months to 10 years old (median 3 years and 2 months). The time between death and accomplishment of the experiment did not exceed 24 hours.
The dogs were randomly divided into three groups of nine animals each in order to evaluate: G1 - total thoracic esophagectomy by the inverting stripping method; G2 - total thoracic esophagectomy and esophageal substitution using the whole stomach; G3 - total thoracic esophagectomy and esophageal substitution using fundus rotation gastroplasty.

\section{Surgical procedures}

\section{GROUP 1}

Each dog was positioned in dorsal recumbency. The ventral neck, thorax and abdomen were clipped, prepared, and draped. A semi-rigid latex was orally placed into the lumen of the stomach. The surgical procedure consisted of three main steps:

1. The abdomen was opened via midline incision extending from the xiphoid to the caudal to the umbilicus. The right gastric branches, right and left gastroepiploic branches were ligated, but the vascular arcades were preserved. The short gastric vessels and the left gastric vessels were ligated (Figure 1) and the liver were retracted to expose the esophageal hiatus. The gastroesophageal junction area was bluntly isolated.

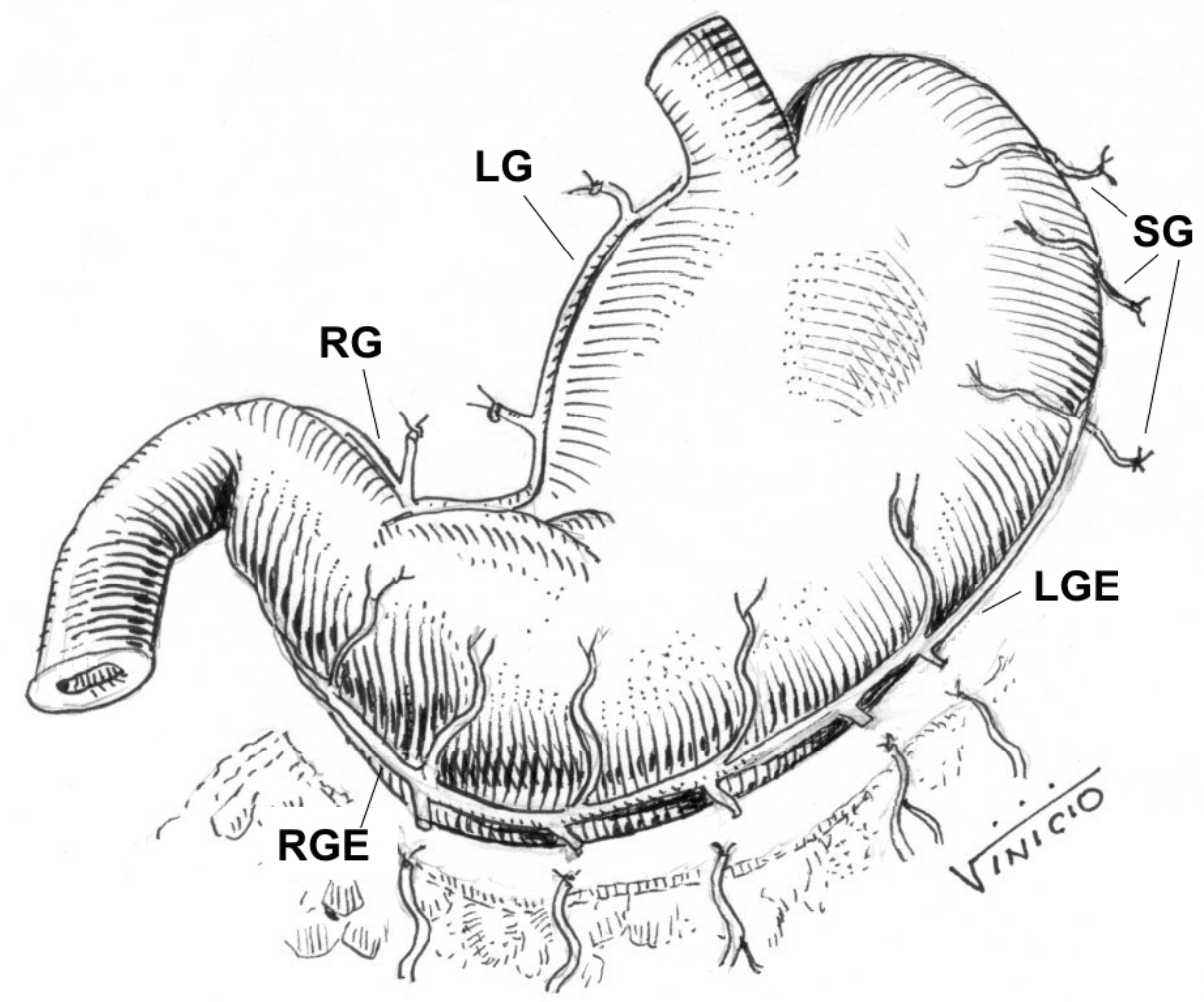

FIGURE 1 - Illustration of the gastric vessels and the ligatures of their tributaries: (RG) Right gastric artery. (LG) Left gastric artery. (SG) Short gastric arteries. (RGE) Right gastroepiploic artery. (LGE) Left gastroepiploic artery 
2. A ventral midline skin incision was made from the middle third of the neck to the manubrium. To expose the caudal cervical esophagus, the trachea and right carotid sheath were retracted to the right.

3. The orogastric tube was pulled out through the mouth so that two atraumatic clamps could be placed in the gastroesophageal junction. An incision was made between the clamps, and the cranial clamp was removed (Figure 2). The tube was pulled caudally to protrude through the abdominal cavity, maintaining its proximal tip at the level of thoracic entrance. The cervical esophagus was transected obliquely about $2 \mathrm{~cm}$ from the thoracic entrance (Figure 2). The caudal edge of the esophagus incision was held to the tube's proximal tip using four equidistant simple interrupted sutures (Figure 3 ). The tube protruding from the abdominal cavity was pulled gently and caudally, allowing the esophagus inverting stripping. The esophagus was pulled through the thorax in the direction of the abdominal cavity (Figure 3 ). The distal esophagus remained attached to the diaphragm, and it was occluded.

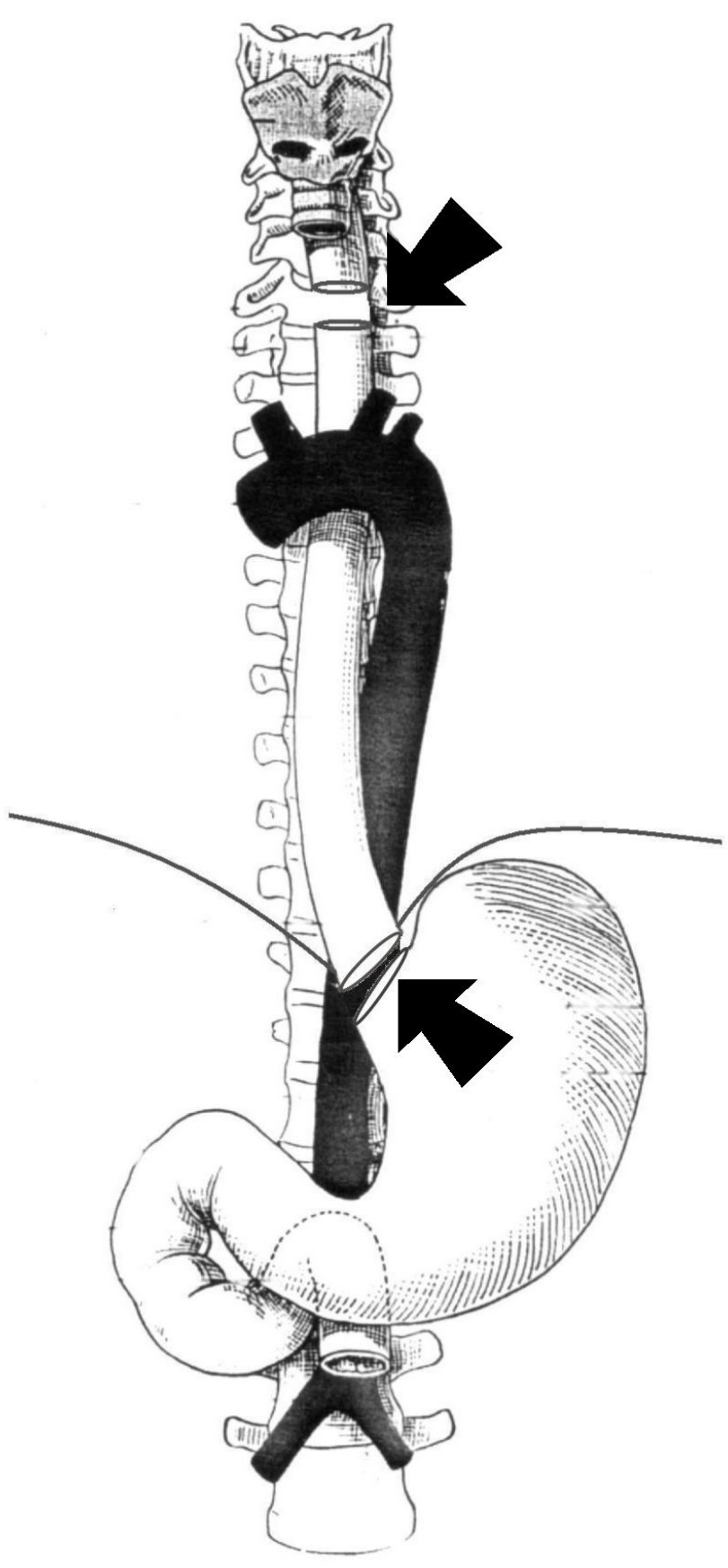

FIGURE 2 - Points of incision of the esophagus (arrows) (cervical esophagus and gastroesophageal junction)

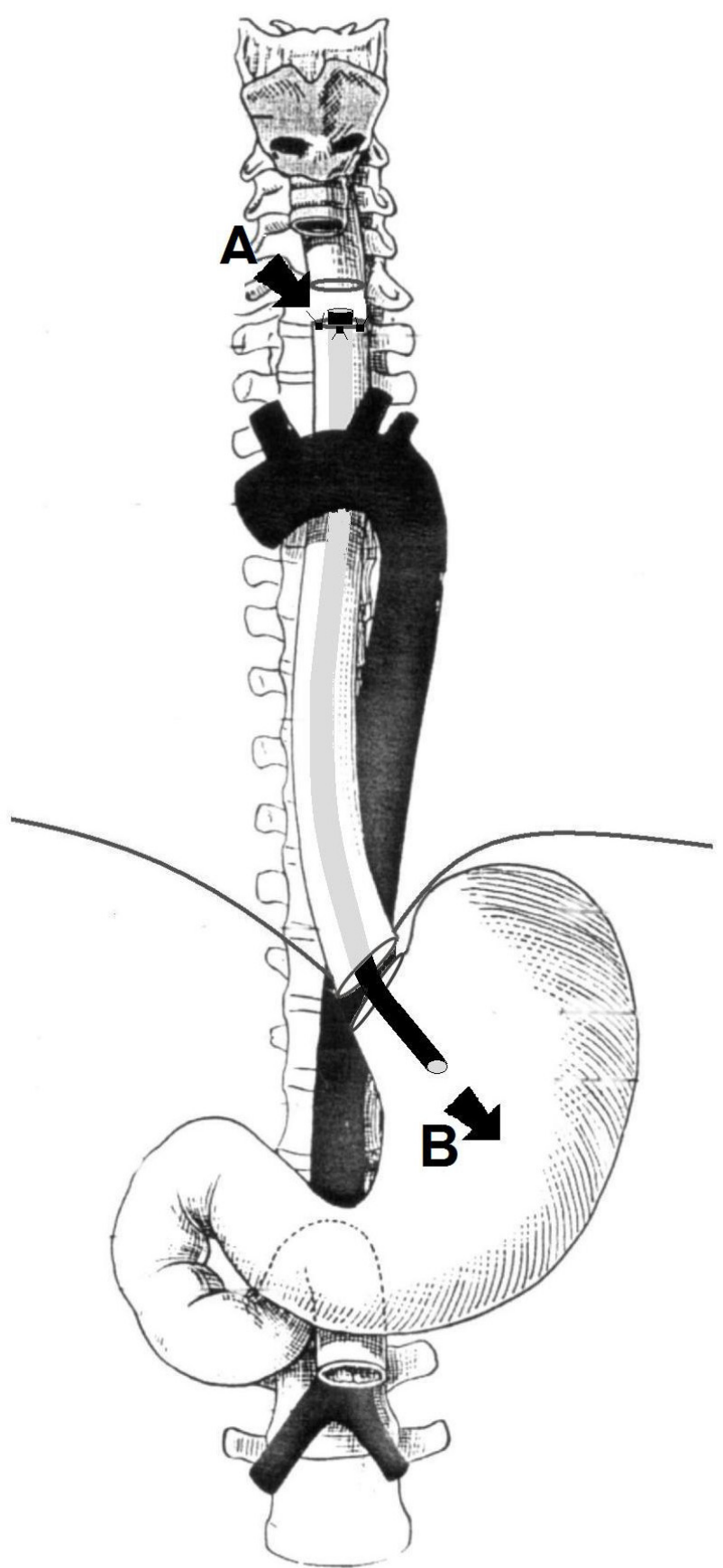

FIGURE 3 - The edge of the esophagus incision was held to the tube's proximal tip using four equidistant simple interrupted sutures (arrow A). The tube protruding from the abdominal cavity was pulled gently and caudally (arrow B), allowing the esophagus inverting stripping 
4. The integrity of the intrathoracic route was evaluated by videoendoscopy. The endoscopy was advanced to the heart base level since after this point the visceral pleura could be injured. $1 \%$ methylene blue solution was used to test for leaks. For this, the operating table was elevated at 15 degrees and a cranial portion of the sternum was removed for better observation.

\section{GROUP 2}

The dogs were positioned and prepared as previously described for Group 1. The vessels and branches were isolated and ligated as previously described for Group 1, for mobilization of the greater and lesser curvature of the stomach. Heineke-Mikulicz pyloroplasty was performed. The gastroesophageal junction was divided, and the cut edge of the stomach was closed in two layers with the first using a continuous suture and the second layer using a continuous inverting seromuscular suture.

Total thoracic esophagectomy by the inverting stripping method was performed as in Group 1. However, a second tube was sutured together with the orogastric tube and the edge of the esophagus, one inside the other (Figure 4). The orogastric tube was removed during esophagectomy. The most distal part of the second tube was sutured to the fundus region of the stomach using four simple interrupted seromuscular sutures.

The stomach was pulled through the thorax in the direction of the cervical region by pulling the proximal tip of the second tube (Figure 5). After tube removal, a stomach stoma was made and anastomosed to the cut end of the cervical esophagus. Three equidistantly suture stitches were initially placed. Additional full-thickness simple continuous pattern sutures were then placed between the stitches until completely closed.

The mobilized stomach wall was anchored to diaphragmatic hiatus with two simple interrupted sutures to prevent subsequent herniation. The celiotomy incision was closed in a routine manner.

The esophagus and mobilized stomach were evaluated using videoendoscopy.

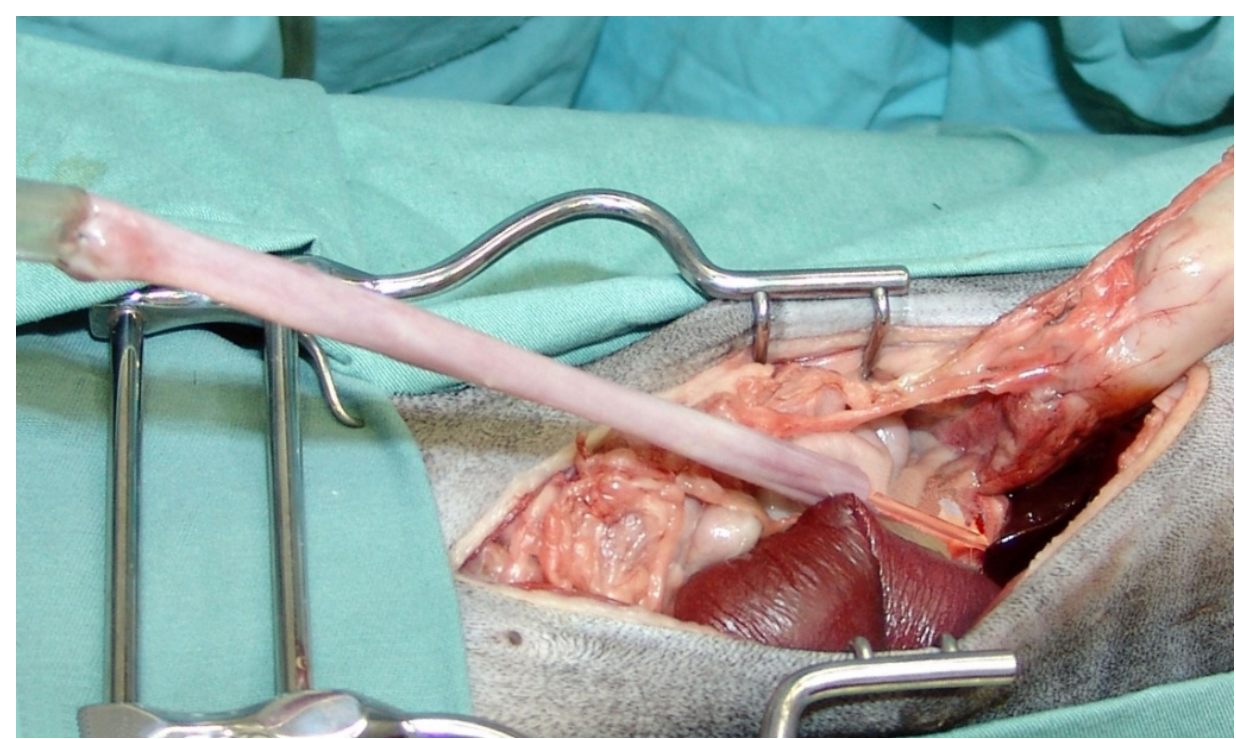

FIGURE 4 - Esophagus removal by traction of the main tube and maintenance of the accessory tube in the thoracic course
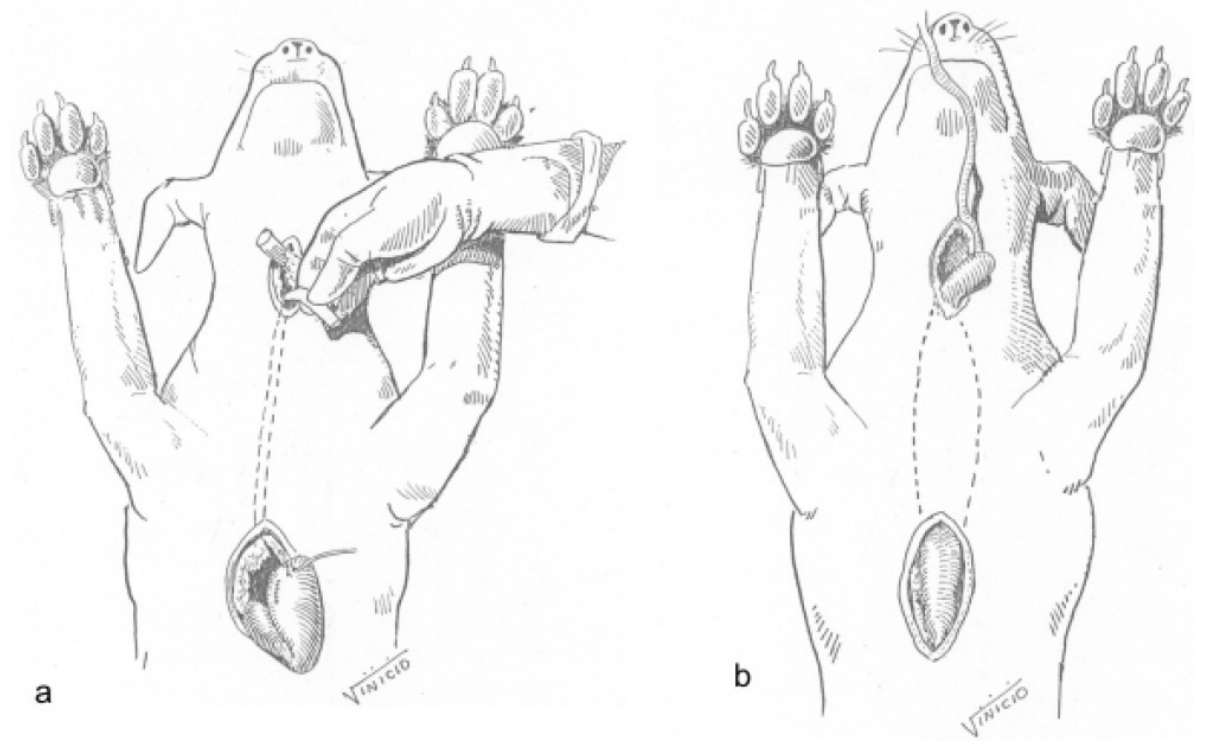

FIGURE 5 - (a) Accessory tube with one of its extremities in the cervical region and another sutured to the stomach. (b) Traction of the accessory tube and exteriorization of the stomach in the cervical region 


\section{$\underline{\text { GROUP } 3}$}

The gastric vessel ligatures, piloroplasty, exposure and cut of the cervical esophagus were similar to those described in Group 2.

Gastroplasty was performed beginning by a horizontal cut of the lesser curvature distally to the gastric stoma. The cut was extended following the greater curvature toward the fundus-corpus region $3 \mathrm{~cm}$ from the pyloric antrus and redirected toward the lesser curvature to a point $1-2 \mathrm{~cm}$ distally to the starting point. The gastric tube with 2 to $3 \mathrm{~cm}$ in diameter was built by the fundus, and most of the gastric corpus and antrus formed the neostomach (Figure 6). The edges of the neoesophagus and neostomach were double-layer apposed.

Total thoracic esophagectomy by the inverting stripping method was performed as described in Group 2, and the most distal part of the second tube was sutured externally to the neoformed gastric tube stoma. The neoformed gastric tube was pulled through the thorax in the direction of the cervical region by pulling the proximal tip of the tube orally. The other procedures were performed as described in Group 2.

Correlation between anatomical proportions and anastomotic tension

Because of the need to compare the interferences of the anatomical measures in the result of the surgical techniques in different sized animals, it was necessary to have the individuals' made uniform through the calculation of their anatomical proportions. The anatomical proportions were calculated for G2 and G3 dogs: between the distance from the larynx to the pubis and from the larynx to the xiphoid (proportion I); between the esophageal substitute length and the distance of the hiatus to the gastroesophageal anastomosis (proportion II); between the distance from the larynx to the xiphoid and the esophageal substitute length (proportion III); between the distance from the gastroesophageal anastomosis to the larynx and the distance from the larynx to the pubis (proportion IV); between the distance that the esophageal substitute transcended the cut end of the cervical esophagus and the distance from the larynx to the pubis (proportion V).

\section{Statistical analysis}

Pearson correlations were used when comparing Proportion V with the other Proportions. In order to compare Proportions V of Groups 2 and 3, the Wilcoxon nonparametric test for two independent samples was used.
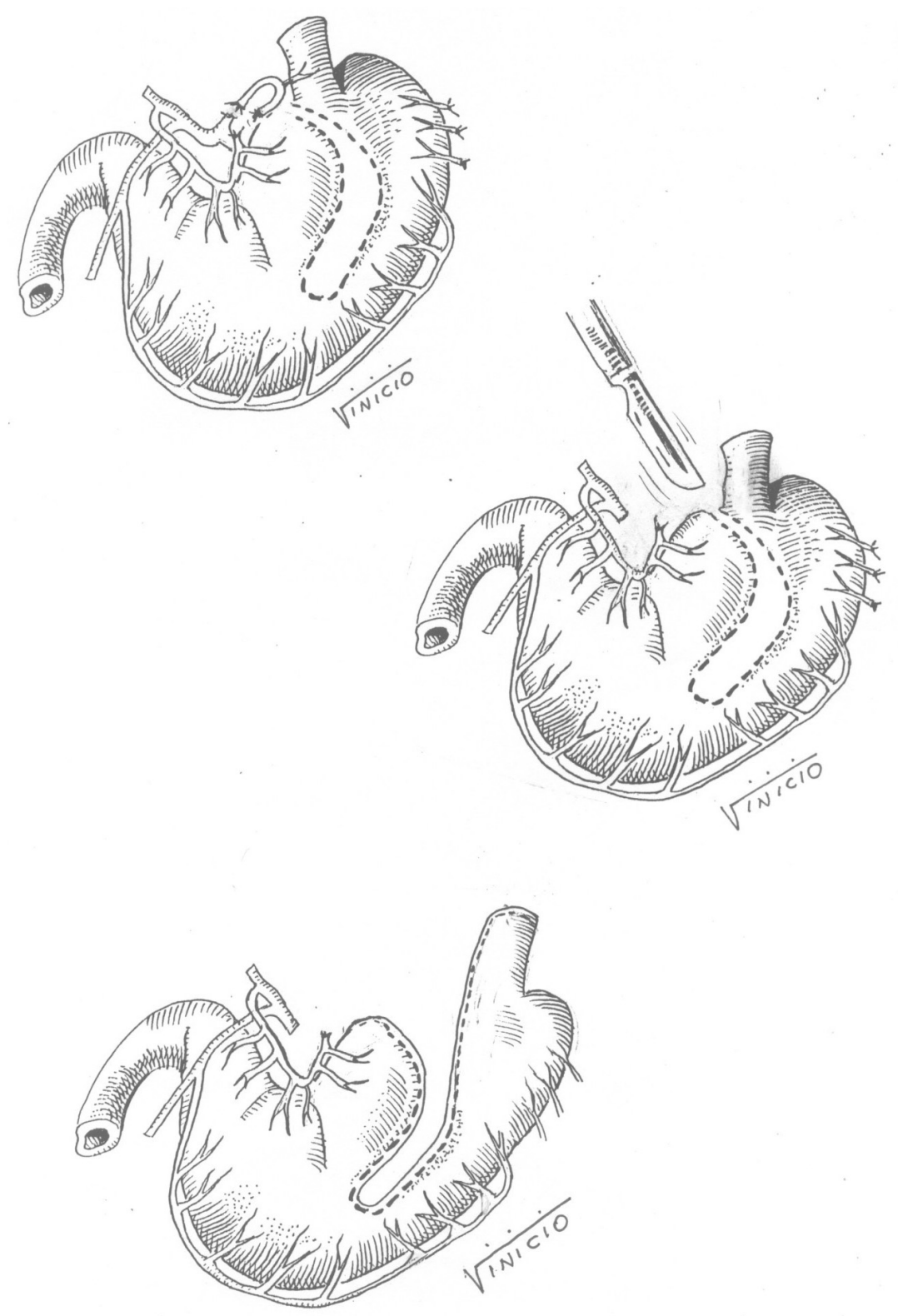

FIGURE 6 - Illustration of the steps for construction of a gastric tube according to the fundus rotation gastroplasty technique

\section{Results \\ GROUP 1}

Esophagectomy by the inverting stripping method showed to be easily performed in all animals since the esophagus was released by slight traction of the tube. According to endoscopic evaluation, small hemorrhage points were observed in the medial $(\mathrm{n}=3)$ and caudal $(\mathrm{n}=1)$ thirds of the pleural cavity. Pleural rupture was verified in three animals. The application of $1 \%$ methylene blue aqueous solution showed pleural rupture in all animals, which was more frequent in the left caudal portion near the diaphragm (Table1). The speed with which the solution filled the thoracic cavity was proportional to the extension and the number of ruptures. 
TABLE 1 - Evaluation of the channel formed after thoracic esophagectomy by the inverting stripping method as shown by endoscopic examination and methylene blue solution

\begin{tabular}{ccccc}
\hline $\begin{array}{c}\text { Dog } \\
\text { (number) }\end{array}$ & $\begin{array}{c}\text { Pleural rupture } \\
\text { (endoscopic } \\
\text { visualization) }\end{array}$ & $\begin{array}{c}\text { Pleural rupture } \\
\text { (methylene } \\
\text { blue) }\end{array}$ & $\begin{array}{c}\text { Third of the } \\
\text { channel affected } \\
\text { by the rupture }\end{array}$ & $\begin{array}{c}\text { Other } \\
\text { endoscopic } \\
\text { findings }\end{array}$ \\
\hline $\mathbf{1}$ & $\mathrm{P}$ & $\mathrm{P}$ & $\mathrm{RCr}, \mathrm{LCr}, \mathrm{LCa}$ & \\
$\mathbf{2}$ & $\mathrm{A}$ & $\mathrm{P}$ & $\mathrm{LCa}$ & $\mathrm{SP}$ \\
$\mathbf{4}$ & $\mathrm{A}$ & $\mathrm{P}$ & $\mathrm{LCa}$ & \\
$\mathbf{5}$ & $\mathrm{P}$ & $\mathrm{P}$ & $\mathrm{RM}$ & $\mathrm{MHp}$ \\
$\mathbf{6}$ & $\mathrm{A}$ & $\mathrm{P}$ & $\mathrm{LM}$ & $\mathrm{SP} / \mathrm{MHp} / \mathrm{CaHp}$ \\
$\mathbf{7}$ & $\mathrm{A}$ & $\mathrm{P}$ & $\mathrm{LCa}$ & $\mathrm{MHp}$ \\
$\mathbf{8}$ & $\mathrm{A}$ & $\mathrm{P}$ & $\mathrm{LCa}$ & \\
$\mathbf{9}$ & $\mathrm{P}$ & $\mathrm{P}$ & $\mathrm{LCa}, \mathrm{RCa}$ & \\
\hline
\end{tabular}

P, present. A, absent. RCr, right cranial. LCr, left cranial. LCa, left caudal. RM, right medial. LM, left medial. RCa, right caudal. SP, slim pleura in the rupture locality. MHp, medial hemorrhagic point. CaHp, caudal hemorrhagic point

\section{GROUP 2}

In one dog, the length of the short gastric vessels was reduced, and the spleen was closely connected to the stomach. Seven dogs showed direct extramural communication between the right and left gastroepiploic arteries, and in two dogs such communication was indirect. Removal of the thoracic esophagus by the inverting stripping method was problematic in one dog showing an anatomic curve proximally to the cardia, which prevented the tube from reaching the stomach. Hence, the esophagogastric junction was sectioned without passing the tube, and the accessory tube was inversely pulled by endoscopic procedures. The esophageal substitute reached the anastomotic region in all animals. The edge of the suspended stomach exceeded the anastomotic region with an average of $2.62 \%$ of the animals' measure (Table 2). Proportions II and III interfered with anastomotic tension (Table 2), and there was no anastomotic tension for Proportion II greater than 1.05 or Proportion III greater than 0.79 . According to the endoscopic evaluation, the region of the esophagogastric anastomosis was closed during the first visualization, but it was easily opened with a touch by a gastroscope in all animals. No openings, leaks or lacerations were detected in the anastomotic region. The esophageal channel consisting of the whole stomach showed to be continuous and without obstructions (Figure 7). The organ's lumen was always greater than the esophageal lumen, with longitudinal folds towards the stomach's positioning.

TABLE 2 - Means of the anatomical proportionalities of dogs in groups 2 and 3

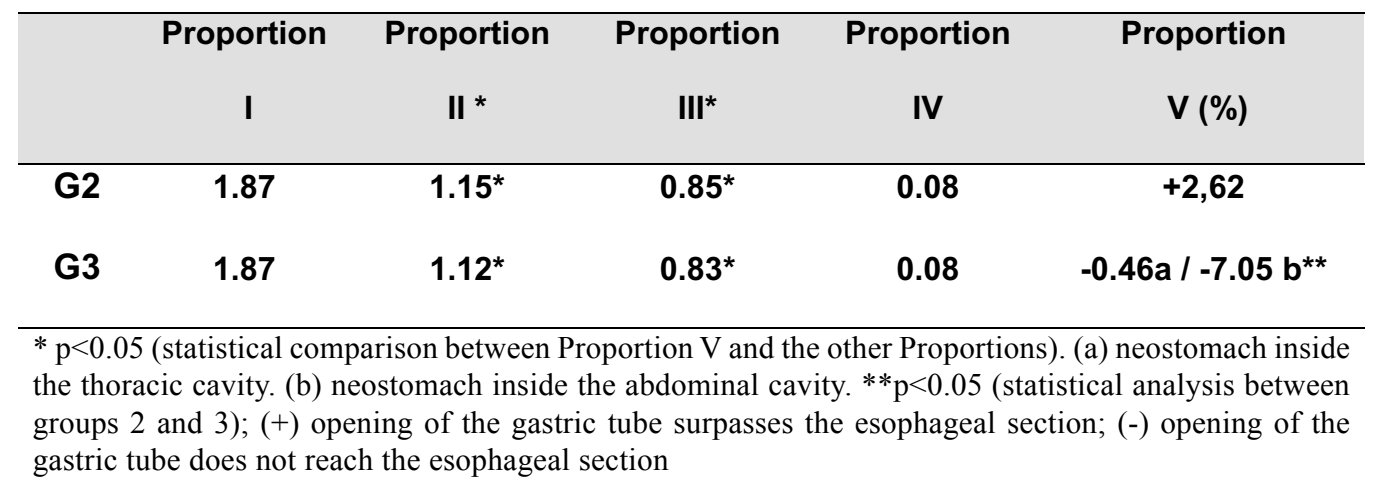




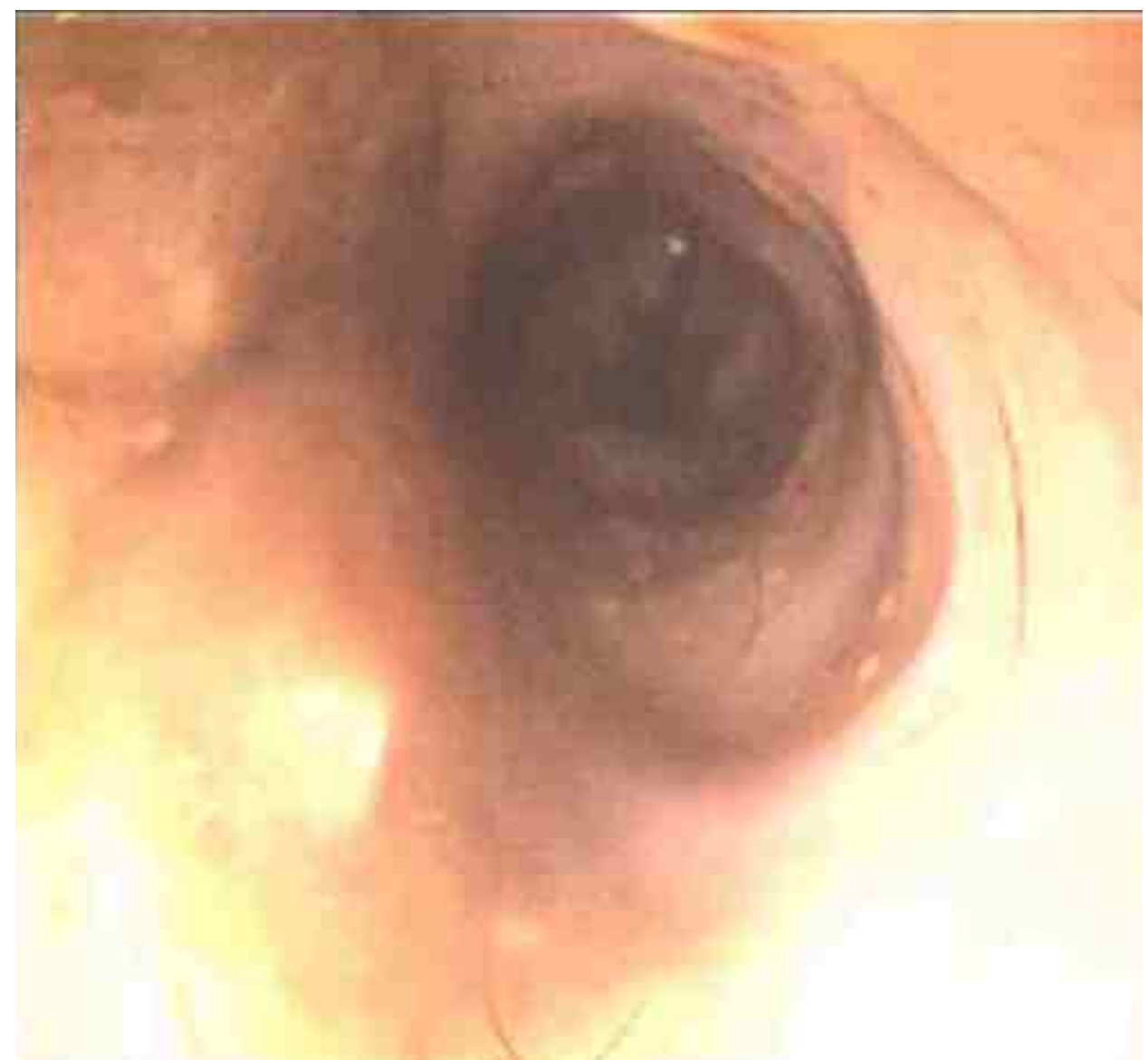

FIGURE 7 - Endoscopic evaluation of the esophagus replacement by the whole stomach: lumen of the suspended stomach

\section{GROUP 3}

In one dog, the left artery and gastric vein were located very close to the splenic vein and the caudal cava vein, and in another the left gastric artery was adjacent to the gastric wall, which required more careful dissection. In three animals, indirect extramural communication between the right and left gastroepiploic arteries was observed. In one dog, the rupture of the suture stitches applied between the esophagus and the tube occurred when the esophagus was removed, and further fixation was necessary. In all dogs, the neostomach formed presented an appendix shape. Except for one case in which gastric tube rupture occurred, the esophageal substitute reached the distal cervical region of all animals; however, that only took place when the neostomach was positioned in the thoracic cavity. Five animals did not show tension in the anastomotic region. The gastric tube extremity was away from the anastomotic region with an average of $0.46 \%$ and $7.05 \%$ of the animals' measure when the neostomach was inside the thoracic and abdominal cavities, respectively (Table 2). There was no anastomotic tension for Proportion II greater than 1.13 or Proportion III greater than 0.84 in the measurements taken with the neostomach in the thoracic cavity. According to endoscopic evaluation, the esophagogastric anastomotic region was closed when firstly visualized, but it was later easily opened with a touch by a gastroscope. No openings, leaks or lacerations were detected in the anastomotic region. The course of the gastric tube was continuous and regular, and showed a larger diameter than that of the cervical esophagus and a smaller diameter than the gastric one. The "neostomach" had a larger diameter and, according to retroflexion visualization, a type of sphincter was observed which separated it from the gastric tube itself (Figure 8). In five dogs, lateralization of the pylorus occurred, which made the passage of the endoscope difficult $(n=1)$ or impossible $(n=4)$.

\section{Discussion}

The choice for the esophageal removal technique depends on a number of factors such as type and location of the primary lesion, safety and feasibility of the approach, patient condition, and even the surgeon's preference ${ }^{8}$. Esophagectomy by the inverting stripping method as used in the present experiment was considered to be a simple and effective procedure to remove the thoracic esophagus in dogs, minimizing surgical time and the complications associated with a thoracic approach. It was based on the technique described by Ferreira ${ }^{9}$, who developed and successfully tested it in 10 dogs, and further in human patients ${ }^{10}$.

Transhiatal resection has the advantages of avoiding thoracotomy, reduced surgical trauma, and less pulmonary complications ${ }^{5,11}$. The endoscopy performed after esophagectomy in the dogs in Group 1 showed few and small areas of bleeding. During evaluation 48 hours after esophagectomy without thoracotomy in dogs, inexpressive hematoma, and no injury to tissue and organs were observed by Ferreira ${ }^{9}$. 


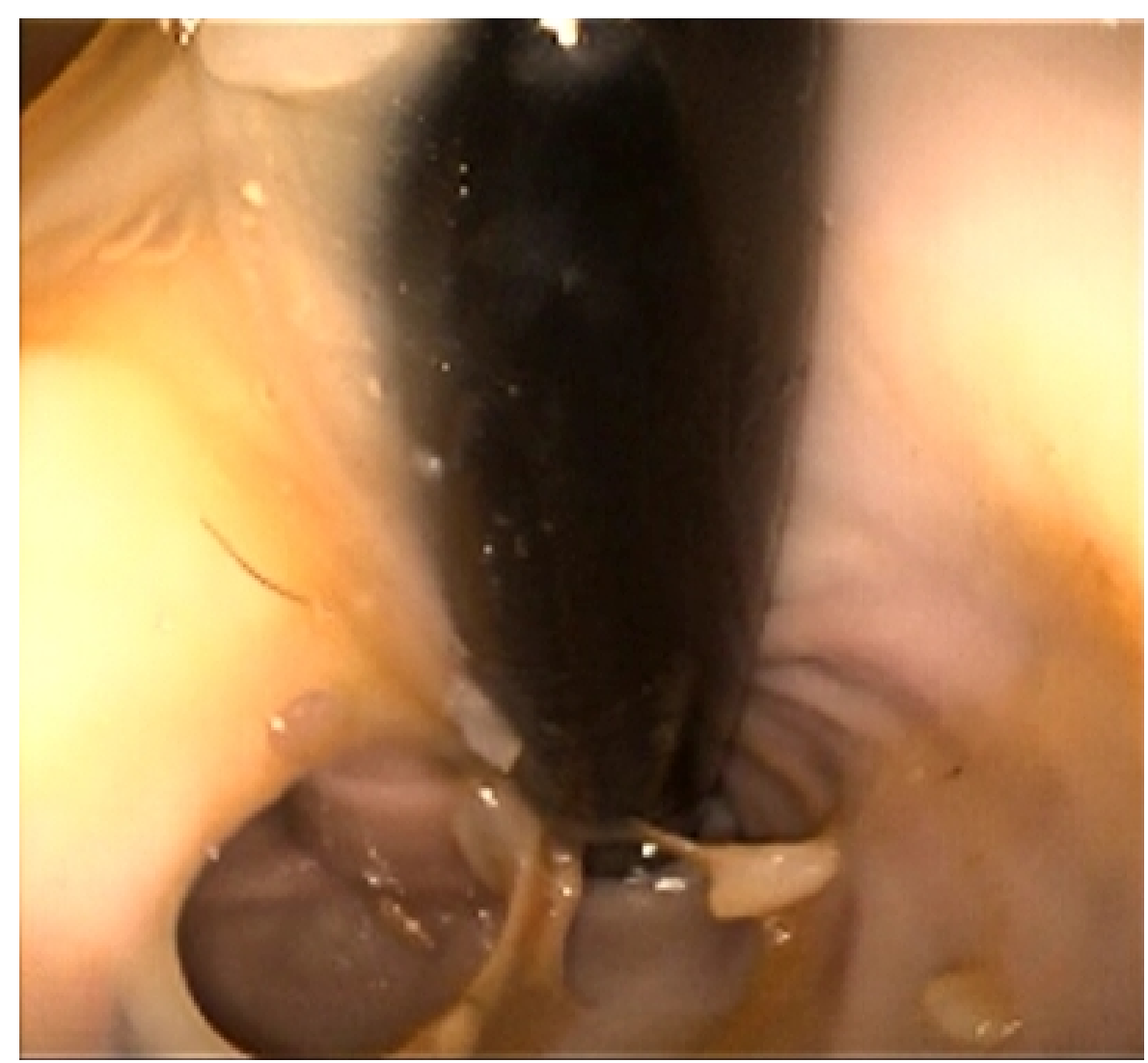

FIGURE 8 - Fundus rotation gastroplasty: retroflexion image showing the limit between the gastric tube and the "neostomach"

An important limitation of esophagectomy by the inverting stripping method is type and extension of the lesion. In cases of infiltrative tumors for example, a direct vision of compromised structures is necessary ${ }^{12}$. Esophagectomy without thoracotomy has been used in human patients especially in cases of megaesophagus ${ }^{8,10,13}$ or corrosive injuries ${ }^{5}$. Since the mediastinal pleura is delicate and directly adhered to the adventice, pleural rupture was observed, by endoscopy and the methylene blue solution test in all animals in Group 1 after esophagectomy. Hence, mechanical ventilation during the procedure and a drainage system postoperative are necessary in cases in vivo.

There are several controversies concerning thoracic esophageal replacement using the stomach as a tube, semitube or whole stomach ${ }^{7,14}$. Besides the factors related to the adequacy of blood supply, in dogs, the capacity of emptying the esophageal substitute in a quadrupedal position should be considered.

Various techniques for isoperistaltic or antiperistaltic gastric tubes have been proposed ${ }^{15,16,17,18,19}$. In the present experiment, fundus rotation gastroplasty was used, which, according to the author ${ }^{20}$ has advantages in human patients, such as the increase in the length of the gastric tube, increase in blood flow at the tip of the gastric tube, and increase in the gastric reservoir since it requires resection of a small part of the gastric corpus.

The tributaries of the right gastric vessels are maintained in the fundus rotation gastroplasty used in human patients ${ }^{20}$. However, in dogs, some differences were observed. The ligature of the left gastric artery and vein was necessary to allow anastomosis of the esophageal substitute with the cervical esophagus. For the same reason, the ligature of the branches of right gastric vessels was caudal rather than that usually used in human patients ${ }^{20}$. In addition, in 8 dogs in Group 3, the gastric tube length was inadequate for tension-free anastomosis, and the neostomach was positioned inside the thoracic cavity. These differences are probably associated with the length of the canine thorax.

On the other hand, esophageal substitution using the whole stomach required less suture procedures. In addition, according to the correlation between anatomical proportions and anastomotic tension, the whole stomach technique, contrarily to fundus rotation gastroplasty, surpassed the anastomotic region, indicating that the use of whole stomach probably induces less anastomotic tension. The significant relation between the absence of tension and Proportion III enables the surgeon to obtain a previous prognosis of the anastomotic tension by observing the patient's measures. The use of the measures of proportionalities allowed the comparison of animals of different sizes, common in the studied specie, therefore although their absolute measures are different, the proportion among their anatomical segments is similar.

The whole stomach occupied more space in the thorax than did the gastric tube, suggesting that the adjacent organs may be compressed by alimentary content. However, radiographic studies in human patients showed that the mobilized stomach acquires a tubular shape during the course of time, and food is propelled chiefly by gravity ${ }^{13}$. This last observation may be a problem in dogs. Bemelman and others ${ }^{7}$ use a tubulized stomach without pyloroplasty 
and not the whole stomach because the gastric remnant must be small and with a low compliance to prevent delayed gastric emptying. In the present study, the gastric tube was smaller than the whole stomach, but gastric tube tension with pylorus deviance in 5 dogs made the endoscope passage difficult, thus suggesting that the same may occur to the passage of food content.

According to the results, it was possible to conclude that total thoracic esophagectomy by the inverting stripping method was an effective procedure to remove the thoracic esophagus, and the whole esophageal substitution using the whole stomach or fundus rotation gastroplasty can be used for thoracic esophageal replacement. The ex-vivo results support further studies to validate the techniques in clinical cases of dogs requiring substitution of the intrathoracic esophagus.

\section{References}

1- Colgrove DJ. Transthoracic esophageal surgery for obstructive lesions caused by Spirocerca lupi in dogs. J Am Vet Med Assoc. 1971;158(12):2073-6.

2- Parker NR, Caywood DD. Surgical diseases of the esophagus. Vet Clin North Am Small Anim Pract. 1987;17:333-57.

3- Ranen E, Shamir MH, Sharar R, Johnston DE. Partial essophagectomy with single layer closure for treatment of esophageal sarcomas in 6 dogs. Vet Surg. 2004;33(4):428-34.

4- Spitz L, Kiely E, Pierro A. Gastric transposition in children-a 21-year experience. J Pediatr Surg. 2004;39(3):276-81.

5- Gupta NM, Gupta R. Transhiatal esophageal resection for corrosive injury. Ann Surg. 2004; 239(3):359-63.

6- Holmberg DL, Kuzma AB, Miller CW. Free bowel transfer for esophageal reconstruction in the dog. Microsurgery. 1991;12:140-4.

7- Bemelman WA, Taat CW, Slors JF, van Lanschot JJ, Obertop H. Delayed postoperative emptying after esophageal resection is dependent on the size of the gastric substitute. J Am Coll Surg. 1995;180(4):461-4. 8- Pinotti HW, Pollara WM, Raia AA. Tratamento cirúrgico do megaesôfago avançado pela esofagectomia subtotal por via cérvico-abdominal sem toracotomia com abertura do diafragma. Rev Assoc Med Bras. 1980,26(10):339-42.
9- Ferreira EAB. Subtotal esophagectomy through cervico-abdominal incision and its possible use in the surgical management of megaesophagus. Rev Paul Med. 1973;82:133-4.

10- Ferreira EAB. Esophagogastroplasty and esophagocoloplasty through the posterior mediastinum without thoracotomy: a preliminary note. Rev Paul Med. 1974;82:142.

11- Gockel I, Sultanov FS, Domeyer M, Goenner U, Junginger T. Developments in esophageal surgery for adenocarcinoma: a comparison of two decades. BMC Cancer. 2007;7:114.

12- Gockel I, Heckhoff S, Messow CM, Kneist W, Junginger T. Transhiatal and transthoracic resection in adenocarcinoma of the esophagus. Does the operative approach have an influence on the long-term prognosis? Word $\mathrm{J}$ Surg Oncol. 2005;3:1-11.

13- Pinotti HW, Cecconello I, Rocha JM, Zilberstein B. Resection for achalasia of the esophagus. Hepatogastroenterology. 1991;38:470-3.

14- Di Benedetto V, Dessanti A. Experimental technique of esophageal substitution: intrathoracic interposition of a pedunculated gastric tube (PGT) preserving cardiac function. Preliminary results. Hepatogastroenterology. 1998;45:2202-5.

15- Swenson O, Magruder LT. Experimental esophagectomy. Surgery. 1944;6:954-63.

16- Yamagishi M, Ikeda N, Yonemoto T. An isoperistaltic gastric tube. Arch Surg. 1970;100:689-92.

17- Akiyama H, Hiyama M, Hashimoto C. Resection and reconstruction for carcinoma of the thoracic oesophagus. Br J Surg. 1976;63:206-9.

18- Yamato T, Hamanaka Y, Hirata S, Sakai K. Esophagoplasty with an autogenous tubed gastric flap. Am J Surg. 1979;137:597-602.

19- Lazar G, Kaszaki J, Abraham S, Horvath G, Wolfard A, Szentpali K, Paszt A, Balogh A, Boros M. Thoracic epidural anesthesia improves the gastric microcirculation during experimental gastric tube formation. Surgery. 2003;134(5):799-805.

20- Büchler MW, Baer HU, Seiler Ch, Schilling M. A technique for gastrosplasty as a substitute for the esophagus: fundus rotation gastroplasty. J Am Coll Surg. 1996;182:241-5.

\section{Acknowledgement}

To Research Support Center (GAP-UNESP) for their valuable contribution in statistical analysis and English review.

\section{Correspondence:}

Dra Sheila Canevese Rahal

Department of Veterinary Surgery and Anesthesiology

Distrito Rubião Jr, s/n

18618-000 Botucatu - SP Brazil

Phone/Fax: (55 14)3811-6054

sheilacr@fmvz.unesp.br

\section{How to cite this article}

Santos CEM, Rahal SC, Damasceno DC, Hossne RS. Esophagectomy and substitution of the thoracic esophagus in dogs. Acta Cir Bras. [serial on the Internet] 2009 Sept-Oct;24(5). Available from URL: $\underline{\text { http://www.scielo.br/acb }}$ 